\title{
A PESCA DO TAMBAQUI, Colossoma macropomum, COM ENFOQUE NA ÁREA DO MÉDIO SOLIMÕES, AMAZONAS, BRASIL.
}

\author{
Luiz. R. F. da COSTA', Ronaldo. B. BARTHEM ${ }^{2}$, Maria Mercedes BITTENCOURT ${ }^{3}$
}

Resumo - Este trabalho avalia a importância da pesca do tambaqui (Colossoma macropomum) nas bacias dos rios Amazonas e Orinoco e, mais especificamente, na região do médio Solimões. As análise foram baseadas em dados de literatura e da pesca praticada pela frota de Tefé no médio Solimões, coletados no mercado de Tefé, entre 1991 e 1995, e a bordo de embarcações da frota pesqueira comercial, entre 1994 e 1995 . A importância relativa da espécie pode alcançar $21 \%$ da produção de pescado em alguns centros urbanos da bacia do Orinoco, na Venezuela; $8 \%$ da Amazônia peruana; e $35 \%$ da Amazônia boliviana. No Brasil, na região do rio Madeira, a importância relativa do tambaqui subiu de $10 \%$ em 1977 para $32 \%$ entre 1984 e 1989. Em Manaus, a espécie já respondeu por $44 \%$ do pescado desembarcado. Porém, a proporção de tambaqui desembarcado nesta cidade sofreu uma grande diminuição nos anos 80 e 90 , chegando a representar apenas $2,5 \%$ do total desembarcado. No médio Solimões, região apontada como a principal área de pesca para esta espécie, são utilizados diversos tipos de aparelhos e explorados diferentes habitats, de acordo com a flutuação do nível da água dos rios. A pesca do tambaqui nesta região é realizada principalmente em lagos, através de malhadeira e rede de cerco, incidindo sobre peixes jovens $(<55 \mathrm{~cm})$. O ambiente formado pela caida de terras nos meandros do rio ("enseada-pausada") é importante para a captura de individuos de maior porte.

Palavras-Chaves: Colossoma, pesca, Solimões, Amazonas, várzea.

Tambaqui, Colossoma macropomum, Fisheries with Focus on an Area on Middle Amazon River, Amazonas State, Brazil

\begin{abstract}
This study evaluates the importance of tambaqui (Colossoma macropomum) in fisheries of the Orinoco and Amazon River basins, through the analysis of published data and new data from the fishing fleet of Tefé, a city in the middle Solimōes River. Data were collected between 1991 and 1995 in Tefé's market and between 1994 and 1995 on board commercial fishing boats. The relative importance of this species can reach $21 \%$ of catches in some landing places of the Orinoco basin, in Venezuela; around $8 \%$ in the Peruvian Amazonia; and 35\% in Bolivian Amazonia. In Brazil, catches of tambaqui increased in the Madeira River region from $10 \%$ in 1977 to $32 \%$ between 1984 and 1989. In Manaus, this species composed up to $40 \%$ of the landed fish in the past. In the 80 's and 90 's, the proportion of tambaqui in landed fish has suffered a drastic reduction, declining to as little as $2,5 \%$. In the middle Solimões, which is the main area of fisheries for this species, catches are made with various fishing gears and in different habitats, accordingly with water level fluctuations. In this region, tambaqui fisheries concentrate inside lakes, where the main gears used are gillnet and purse seine, and the catch is composed of the young fish $(<55 \mathrm{~cm})$. The habitats created by river bank collapse ("enseada-pausada") are important for the catch of larger individuals.
\end{abstract}

Key-Words: Colossoma, fisheries, Solimões, Amazonas, várzea.

\section{INTRODUÇÃO}

\section{O tambaqui (Colossoma} macropomum) é o maior caracídeo da
América do Sul, atinge tamanhos maiores que 1 metro de comprimento e $30 \mathrm{~kg}$ de peso e apresenta uma distribuição que abrange as bacias dos

${ }^{1}$ C. P. 96, 68005-970 Santarém, PA

${ }^{2}$ Museu Paraense Emílio Goeldi (MPEG), C.P. 399, 66040-170

${ }^{3}$ Instituto Nacional de Pesquisas da Amazônia (INPA), C. P. 478, 69011-970 
rios Orinoco e Amazonas. Esta espécie habita os principais rios da região Amazônica e tem seu ciclo de vida associado às planícies de inundação: os jovens (comprimento $<55 \mathrm{~cm}$ ) são abundantes em lagos e áreas alagadas, onde se alimentam de zooplâncton, frutas e sementes; e os adultos (comprimento $>55 \mathrm{~cm}$ ) realizam migrações no rio principal durante a seca, cujos movimentos estão relacionados à dispersão e à reprodução da espécie (Honda, 1975; Goulding, 1979; 1980; Carvalho, 1981; Goulding \& Carvalho, 1982; Novoa et al, 1984; Novoa, 1990; Araújo-Lima \& Goulding, 1997).

Este estudo avalia a importância do tambaqui no desembarque dos principais centros urbanos das bacias dos rios Amazonas e Orinoco e descreve sua pesca na região apontada como uma das áreas pesqueiras mais importante para a espécie, o médio Solimões (Petrere Jr., 1978b e 1983). O estudo é baseado principalmente no desempenho da frota pesqueira que desembarca no município de Tefé, onde são feitas considerações sobre a sazonalidade do desembarque e da comercialização dos tambaquis, as técnicas de pesca utilizadas, a composição em comprimento da captura e os tipos de ambientes explorados em relação à oscilação do nivel do rio.

\section{MATERIAL E MÉTODOS}

\section{Análise da pesca do tambaqui nas bacias dos rios Amazonas e Orinoco.}

A avaliação da importância do tambaqui nas pescarias das bacias dos rios Amazonas e Orinoco foi baseada nos dados de desembarque publicados por Novoa \& Ramos (1978) na Venezuela, Barthem et al. (1995) no Peru, INPA (1995) na Colômbia, Lauzanne et al. (1990) na Bolívia e Petrere Jr. (1978b, 1983 e 1985), Goulding (1979), Merona \& Bittencourt (1988), Boischio (1992), Barthem (1995, 1999a e 1999b), Barthem et al. (1995), Ruffino \& Isaac (1994) e Batista (1998) no Brasil.

\section{Análise da Pesca do Tambaqui no Médio Solimões}

A caracterização da pesca do tambaqui pela frota pesqueira que desembarca em Tefé foi feita com base (i) nos dados coletados no mercado desta cidade entre outubro de 1991 e novembro de 1995 e (ii) nos dados obtidos a bordo de embarcações da frota comercial da região entre janeiro de 1994 e dezembro de 1995.

\section{(a) Desembarque no Mercado}

Os dados obtidos durante o desembarque do pescado para abastecer o mercado de Tefé forneceram informações sobre o modo de pesca, o ambiente que se pescou, a quantidade de pescado capturado pela frota que aporta nesta cidade e o que é desembarcado nela e a composição, em tamanho, do pescado capturado. A distinção entre o que é capturado e o que é desembarcado se deve ao fato que algumas embarcações de pesca, especialmente as de maior porte, desembarcam nesta cidade apenas parte de sua produção. Esta é vendida 
com a finalidade de gerar renda para a compra adicional de gelo e combustível necessários para prosseguir a viagem até Manaus, que é o porto de destino desta produção. Devido a isto, foi necessário considerar separadamente as quantidades relativas ao pescado que foi desembarcado em Tefé daquele que estava presente na urnas dos barcos de pesca antes do desembarque, sendo este último considerado quantidade capturada nesta pescaria.

As informações foram obtidas por meio de entrevistas ao encarregado do barco de pesca, da pesagem do pescado desembarcado no mercado e da medição de comprimento dos tambaquis. Os encarregados pelas embarcações de pesca foram entrevistados no porto de Tefé no dia do desembarque. A entrevista era baseada num questionário padrão que solicitava informações sobre o modo de pesca, o ambiente que se pescou e a estimativa da captura (EC) do encarregado sobre a quantidade de pescado, total e por espécie, capturada naquela viagem. Independente desta informação, uma balança foi posicionada na entrada do mercado para pesar o pescado desembarcado e comercializado neste porto. Esta pesagem foi adaptada ao sistema de transporte de pescado do porto ao mercado desta cidade. O pescado é desembarcado por pessoas denominadas de carregadores que levam, em suas cabeças, uma caixa com grande quantidade de pescado do porto ao mercado. Antes de descarregar o pescado, os carregadores mais a sua carga eram pesados numa balança com a capacidade de até $300 \mathrm{~kg}$, situada na entrada do mercado. O peso do pescado (PP) era obtido da diferença entre o peso do carregador com pescado e sem o pescado, este último obtido regularmente depois das atividades de desembarque, e relacionado com a entrevista realizada no porto. Esta rotina ocorria diariamente duas vezes ao dia: das 6:00 h às $10: 30 \mathrm{~h}$ e das $15: 00 \mathrm{~h}$ às 17:30 h.

A medição sistemática do comprimento furcal de uma amostra de tambaqui desembarcados em Tefé era feita semanalmente dentro do mercado e, esporadicamente, em barcos de pesca que se destinavam ao porto de Manaus.

\section{(b) Pesquisa a Bordo}

As pesquisas a bordo de embarcações da frota pesqueira de Tefé foram feitas nos períodos de enchente, cheia, vazante e seca de 1994 e 1995, onde foram obtidos dados sobre tipos de ambientes explorados, aparelhos de pesca empregados e composição em tamanho dos tambaquis capturados. As medidas de comprimento foram obtidas de amostras logo após sua captura em pescarias comerciais nas áreas alagadas e nas margens dos rios Solimões, Japurá e Aranapu. Dados sobre o nível da água foram obtidos na Estação Fluviométrica das Missões (Tefé-AM), durante os anos de 1991 a 1995. 


\section{RESULTADOS}

\section{Importância do tambaqui nas} pescarias das bacias dos rios

\section{Amazonas e Orinoco.}

O tambaqui é um importante recurso pesqueiro das bacias dos rios Amazonas e Orinoco, não ocorre na bacia do rio Tocantins, e tem destaque nos desembarques de importantes núcleos urbanos da Venezuela, Peru, Bolivia e Brasil (Fig. 1). O tambaqui é explorado na bacia do rio Orinoco pelas frotas venezuelana e colombiana, principalmente a primeira. Nesta região não diferenciam o desembarque do tambaqui da pirapitinga (Pyaractus brachypomus), sendo suas estatísticas de desembarque apresentadas em conjunto. A captura de ambas espécies representou entre 716 e 1.130 toneladas anuais ou 12,1 e $21,1 \%$ do desembarque total na Venezuela, nas cidades de Tucupita, Barrancas e Ciudad Bolivar, entre os anos de 1972 e 1976 (Novoa \& Ramos, 1978). Na Colômbia, o desembarque de ambas espécies é mais modesto, tendo alcançado 16,8 toneladas em 1994 , ou $0,3 \%$ do desembarque total (INPA, 1995) (Tab. 1). Na bacia do rio Amazonas, o tambaqui é explorado

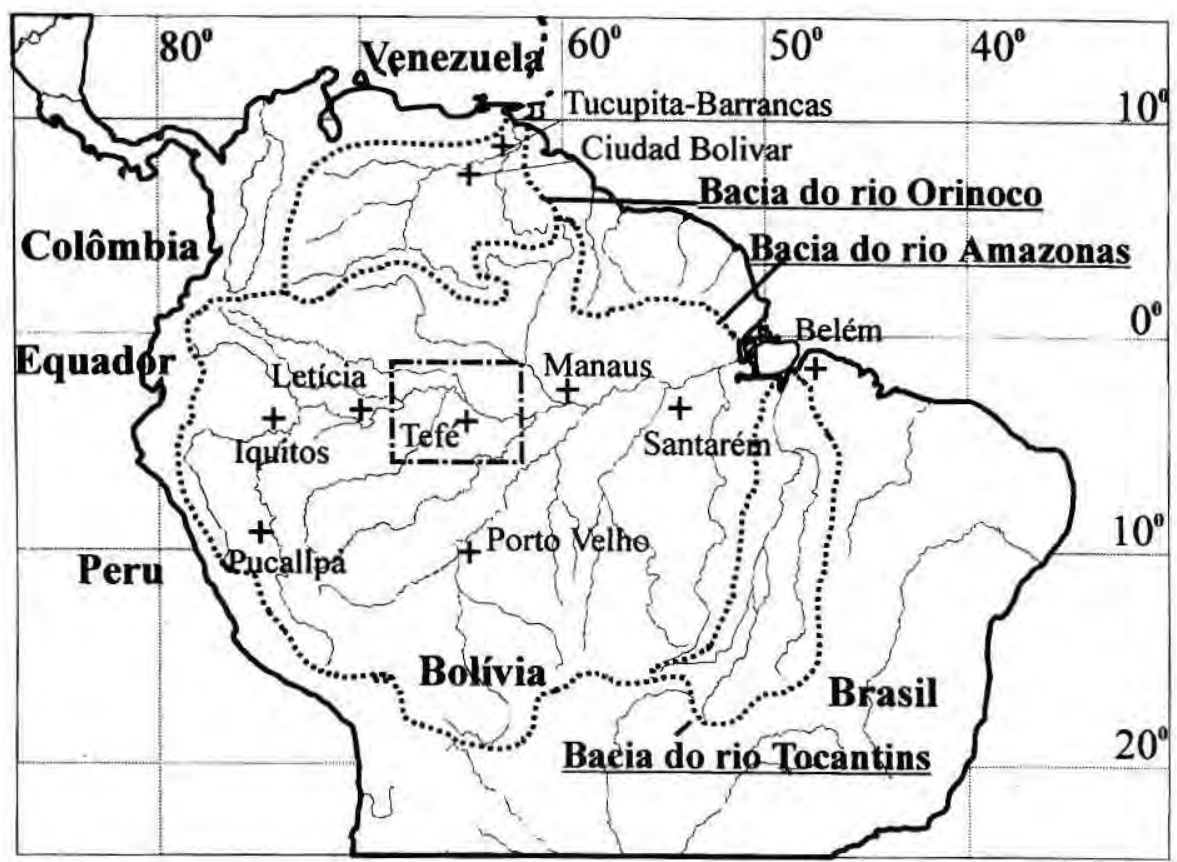

Figura 1. Norte da América do Sul mostrando: o limite das bacias dos rios Orinoco, Amazonas e Tocantins (linha pontilhada), a localização das principais cidades das bacias dos rios Orinoco e Amazonas que recebem o desembarque de tambaquis (+) e a delimitação da região do médio Solimões (retângulo). 
pelas frotas pesqueiras de Peru, Colômbia, Bolívia e Brasil.

$\mathrm{O}$ tambaqui não possui importância destacada nos principais centros urbanos da Amazônia peruana e colombiana, como apresentou nos mercados venezuelanos, mas é ainda uma espécie de destaque. $\mathrm{Na}$ Amazônia peruana, sua captura média anual foi de 275 toneladas ou $3,1 \%$ do desembarque total para o periodo entre 1980 e 1992 na região de Loreto, cuja principal cidade é Iquitos; e 105 toneladas ou $2,8 \%$ do desembarque anual para o período entre 1980 e 1991 na região de Ucayali, onde Pucallpa é a principal cidade (Barthem et al., 1995) (Tab. 1). Na Amazônia colombiana, o tambaqui é consumido principalmente pela população rural, sendo pouco comercializado nos mercados das principais cidades, como Letícia, no rio Amazonas, e Araracuara e La Pedrera, no rio Caquetá. Por outro lado, o tambaqui é uma espécie de destaque na Amazônia boliviana e brasileira.

A Amazônia boliviana abrange a região do alto rio Madeira, incluindo os rios Beni, Madre de Dios, Mamoré e Itenez. A cidade de Trinidad é o principal porto de desembarque para o pescado capturado no médio Mamoré e o desembarque de tambaqui representou cerca de $35 \%$ do total desembarcado entre janeiro de $1986 \mathrm{e}$ maio de 1987 , que foi de 370 toneladas. Mas este valor não representa a captura total do tambaqui na Amazônia boliviana, pois parte do que é capturado pela frota estabelecida principalmente nas cidades de
Riberalta, Cachuela Esperanza e Guayaramerin é destinada ao mercado brasileiro (Lauzanne et al., 1990). A cidade de Porto Velho é o principal centro urbano do rio Madeira e está situada na Amazônia brasileira. A captura do tambaqui nesta cidade foi de 58 toneladas ou $10 \%$ do desembarque total em 1977, período em que o esforço de pesca estava direcionado para os bagres (Goulding, 1979). Na década de 80 , o consumo local passou a sustentar a maior parte da atividade pesqueira e o tambaqui se tornou então a espécie de maior importância econômica da cidade, apresentando uma captura média de 236,5 toneladas anuais ou $20 \%$ do total desembarcado no período entre 1984 e 1989 (Boischio, 1992) (Tab. 1).

A maior captura do tambaqui se dá na Amazônia central brasileira, ao longo do rio Amazonas-Solimões, e da porção inferior de seus principais tributários, como Jutaí, Juruá, Japurá, Purus e Madeira. Manaus é a principal cidade desta região e também o principal porto de desembarque de tambaqui, cuja produção se destina tanto para o consumo interno como para a exportação. Esta espécie foi o pescado mais importante até o final da década de 70 , quando a captura anual atingiu cotas superior a $13 \mathrm{mil}$ toneladas ou cerca de $40 \%$ do total desembarcado, sendo a maior parte, $32 \%$ a $37 \%$ do total de tambaquis, obtida na região do médio SolimõesJapurá (Petrere Jr., 1978b, 1983 e 1985). A cidade de Tefé é o principal centro urbano da região do médio 
Solimões-Japurá e o seu desembarque anual está situado em torno de 2.000 toneladas, dos quais cerca de $3 \%$ seriam de tambaqui (Barthem,1999).

$\mathrm{O}$ desembarque de tambaqui em Manaus continuou expressiva nas décadas de 80 e 90 , mas seu volume e importância relativa no desembarque total foram reduzidos. Seu desembarque caiu para valores entre 2 e $7 \mathrm{mil}$ toneladas anuais ao longo da década de 80 , que representam de 6 a $27 \%$ do to- tal desembarcado, passando a ser o segundo pescado mais importante desta cidade (Merona \& Bittencourt, 1988). $\mathrm{Na}$ década de 90 seu desembarque oscilou entre 5.232 e 656 toneladas anuais ou $23,4 \%$ e $2,5 \%$ do desembarque total, chegando a ser a espécie mais importante em 1995 e a sétima em 1994 (Batista, 1998).

Santarém é o principal ponto de desembarque de pescado na região do médio e baixo Amazonas. O

Tabela 1. Desembarque de tambaqui nos principais portos das bacias Amazônica e Orinoco em relação ao desembarque total.

\begin{tabular}{|c|c|c|c|c|c|}
\hline Bacia & Local & $\begin{array}{l}\text { Desembarque } \\
\text { Anual (toneladas) }\end{array}$ & $\begin{array}{l}\text { Tambaqui em } \\
\text { relação ao total (\%) }\end{array}$ & Ano & Fonte \\
\hline Orinoco* & Colõmbia (Orinoquia) & 5.159 & 0,3 & 1994 & INPA (1995) \\
\hline Orinoco" & $\begin{array}{c}\text { Venezuela (Tucupita, } \\
\text { Barrancas e Ciudad } \\
\text { Bolivar) }\end{array}$ & $4.962 \cdot 8.424$ & $12,1 \cdot 21,1$ & $1972-1976$ & $\begin{array}{c}\text { Novoa \& } \\
\text { Ramos }(1978)\end{array}$ \\
\hline Amazonas & Peru (Loreto: lquitos) & $883-14 \cdot 163,3$ & $2,2-8,6$ & $1980-1992$ & $\begin{array}{c}\text { Barthem et al } \\
\text { (1995) }\end{array}$ \\
\hline Amazonas & $\begin{array}{l}\text { Peru (Ucayali: } \\
\text { Pucalpa) }\end{array}$ & $1.783-9.572$ & $0,8-5,7$ & $1980-1991$ & $\begin{array}{c}\text { Barthem et ai } \\
\quad(1995)\end{array}$ \\
\hline Amazonas & Bolivia (Trinidad) & 4.040 & 35 & $1986-1987$ & $\begin{array}{l}\text { Lauzanne et } \\
\text { al. }(1990)\end{array}$ \\
\hline Amazonas & $\begin{array}{l}\text { Brasil (Rondônia: } \\
\text { Porto Velho) }\end{array}$ & 602 & 10 & 1977 & $\begin{array}{l}\text { Goulding } \\
(1979)\end{array}$ \\
\hline Amazonas & $\begin{array}{l}\text { Brasil (Rondônia: } \\
\text { Porto Velho) }\end{array}$ & $927,5-1.487,5$ & $22,9-32,5$ & $1984-1989$ & $\begin{array}{c}\text { Boischio } \\
\text { (1992) }\end{array}$ \\
\hline Amazonas & $\begin{array}{c}\text { Brasil (Amazonas: } \\
\text { Tefé) }\end{array}$ & $1.491-1.660$ & $3,8-3,8$ & $1992-1993$ & $\begin{array}{l}\text { Barthem } \\
\text { (1999) }\end{array}$ \\
\hline Amazonas & $\begin{array}{l}\text { Brasil (Amazonas: } \\
\text { Manaus) }\end{array}$ & $30.243,9$ & 44 & 1976 & $\begin{array}{l}\text { Petrere Jr. } \\
(1978 \mathrm{~b} e \\
1985)\end{array}$ \\
\hline Amazonas & $\begin{array}{c}\text { Brasil (Amazonas: } \\
\text { Manaus) }\end{array}$ & $20-30 \mathrm{mil}$ & $6,4-27,5$ & $1980-1986$ & $\begin{array}{c}\text { Merona \& } \\
\text { Bittencourt } \\
(1988)\end{array}$ \\
\hline Amazonas & $\begin{array}{l}\text { Brasil (Amazonas: } \\
\text { Manaus) }\end{array}$ & $22.322-25.804$ & $2,5-23,4$ & $1994-1996$ & Batista (1998) \\
\hline Amazonas & $\begin{array}{l}\text { Brasil (Pará: } \\
\text { Santarém) }\end{array}$ & 3.713 & 5,6 & 1992 & $\begin{array}{c}\text { Ruffino \& } \\
\text { Isaac (1994) }\end{array}$ \\
\hline
\end{tabular}

* Incluindo Colossoma macropomum e Pyaractus brachypomus 
desembarque do tambaqui nesta cidade e em 1992 representou cerca de $5,6 \%$ do desembarque total, que se situava em torno de 3.700 toneladas (Ruffino \& Isaac, 1994) (Tab. 1). A importância do tambaqui no desembarque de pescado na região da foz Amazônica, onde a cidade de Belém é o principal centro de desembarque, é pouco expressiva.

\section{A Pesca do Tambaqui no Médio Solimões}

\section{(a) Área de Pesca}

O médio Solimões abrange a região da confluência dos rios Solimões e Japurá, incluindo os paranás Auati-Paraná (acima da foz do rio Jutaí) e Copeá (acima da cidade de Coari) e cujo principal centro urbano é a cidade de Tefé. Esta região pertence aos municipios de Tefé, Alvarães, Uarini, Fonte Boa, Maraã, Juruá e Jutaí, (Fig. 2).

\section{(b) Tipos de ambientes}

A Figura 3 apresenta um esquema que procura caracterizar os oito ambientes da várzea do médio Solimões definidos pelos pescadores como importantes para a pesca do tambaqui. Estes ambientes são: (i) "boca" (foz de pequenos rios, paraná ou lago); (ii) "enseada-pausada" (curvas de rio onde a correnteza desmoronou as margens formando enseadas com galhos e troncos de árvores); (iii) "igapó" (floresta alagada); (iv) lago; (v) paraná; (vi) praia; (vii) ressaca e (viii) rio. Alguns ambientes existem em qualquer época do ano, como "boca", paraná, lago e rio; outros só ocorrem nos periodos de águas altas, como "capim- matupá" e "igapó"; e os demais são mais evidentes nos períodos de águas baixas, como "enseada-pausada", praia e ressaca. A pesca de tambaquis nestes ambientes depende do nivel do rio e do estágio do ciclo de vida em que se encontram os exemplares desta espécie.

\section{(c) Tipos de aparelhos de pesca utilizados}

A pesca na Amazônia é feita com uma grande diversidade de aparelhos de pesca, cada qual mais eficiente para um conjunto de espécies alvo, conforme o ambiente e o nivel do rio. A Tabela 2 apresenta uma breve descrição dos 11 tipos de aparelhos de pesca identificados na região do médio Solimões utilizados na pesca do tambaqui.

\section{(d) Desembarque e captura em peso.}

A relação entre a estimativa da captura (EC) e o peso do pescado (PP) das embarcações que desembarcaram toda a sua captura em Tefé permitiu elaborar uma equação linear que corrigisse as estimativas de pescado fornecidas pelos encarregados das embarcações de pesca em geral. A regressão resultante apresentou parâmetros altamente significativos, que pode ser descrita da seguinte forma:

$$
\begin{gathered}
\mathrm{PP}=22,7238+0,9662 . \mathrm{EC} \\
\left(\mathrm{n}=20.115, \mathrm{P}<0,001, \mathrm{r}=0,916, \mathrm{r}^{2}=0,839\right) .
\end{gathered}
$$

A equação resultante foi utilizada para corrigir as informações do encarregado (EC) e estimar o volume de pescado que se encontrava nas embarcações (CC) que foram entrevistadas em 


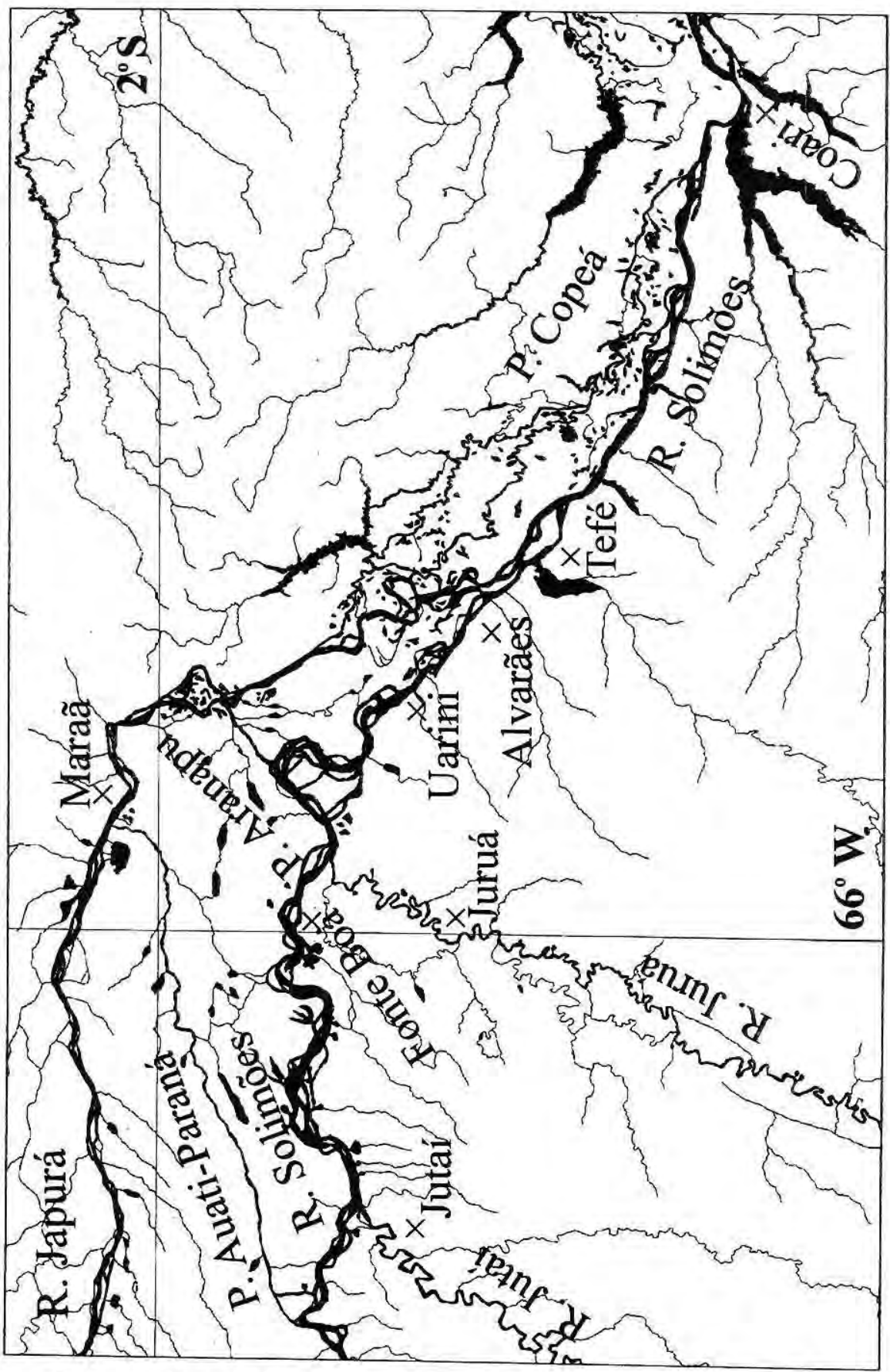

Figura 2. Região do médio Solimões, onde atua a frota pesqueira de Tefé (X-cidade, $R$ - - rio e P.- paraná), Amazonas, Brasil. 


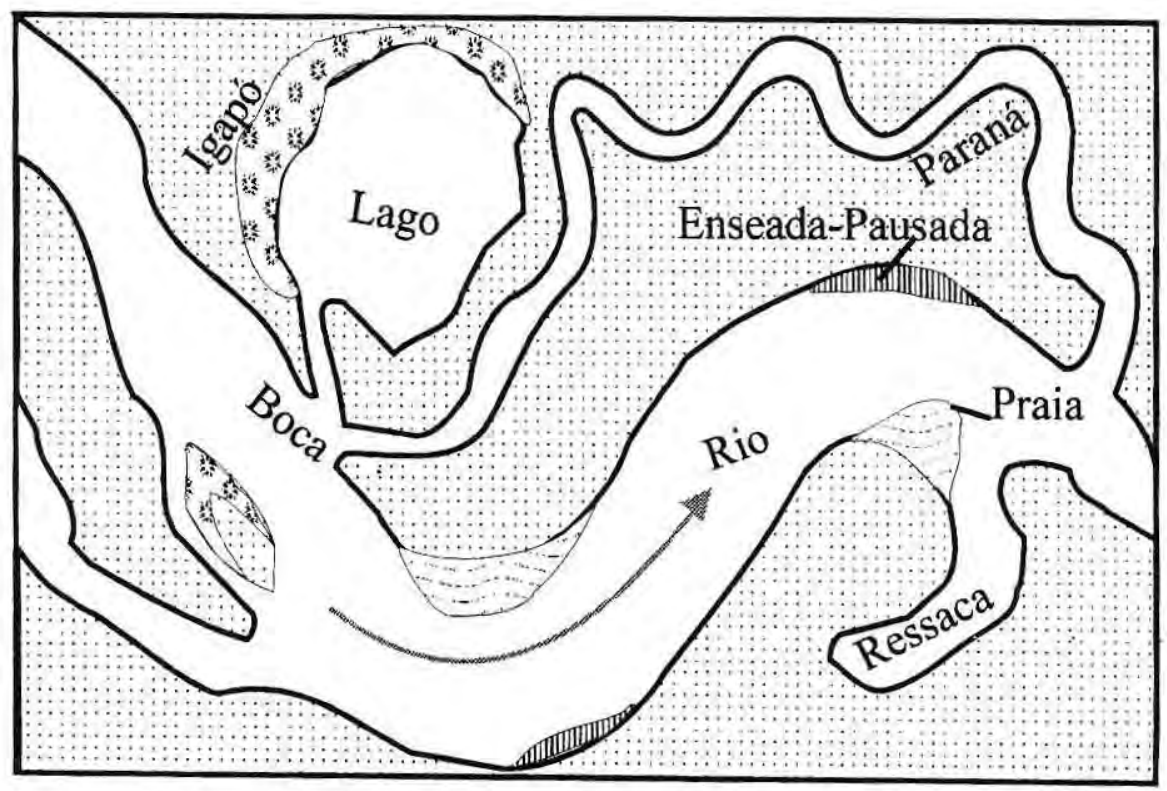

Figura 3. Esquema dos tipos de ambientes explorados pelos pescadores do médio Solimòes, Amazonas, Brasil.

Tabela 2. Lista e breve descrição dos 11 tipos de aparelhos de pesca que capturam tambaqui na região de médio Solimões, Amazonas, Brasil.

\begin{tabular}{ll}
\hline Tipos de Aparelhos de Pesca & \multicolumn{1}{c}{ Descriçâo } \\
\hline Arpăo & $\begin{array}{l}\text { Haste de madeira provida de uma ponta de ferro; comum na pesca do pirarucu, mas } \\
\text { também utilizado na pesca de tambaquis grandes. }\end{array}$ \\
Arrastadeira & $\begin{array}{l}\text { Rede de arrasto de praia; utilizado em margens do rio limpa de galhos e troncos. } \\
\text { Caniço }\end{array}$ \\
Espinhel & $\begin{array}{l}\text { Uma linhna comprida, com as duas pontas amarradas à margem, com várias linhas } \\
\text { menores com anzóis. }\end{array}$ \\
Flecha/flechão & $\begin{array}{l}\text { Uma vara oca com um arpăo ou tridente na ponta lançado por um arco ou mesmo } \\
\text { pela măo, }\end{array}$ \\
Linha de măo & $\begin{array}{l}\text { Uma linha comprida com um anzol médio e segura pelo pescador. } \\
\text { Rede de emalhar passiva, amplamente utilizada em ambientes sem correnteza. }\end{array}$ \\
Malhadeira & Uma combinaçăo de malhadeira e arrastadeira; utilizada nas margens do rio. \\
Rede malhadeira & $\begin{array}{l}\text { Rede de cerco utilizada em águas fundas ou áreas onde o fundo seja livre de } \\
\text { obstáculos. }\end{array}$ \\
\hline Redinha & lanterna.
\end{tabular}


Tefé. A Tabela 3 apresenta a quantidade de pescado pesado (PP) e a captura corrigida (CC) dos encarregados das embarcações obtidas durante as entrevistas.

Considerando que a frota que desembarcou em Tefé havia pescado na área do médio Solimões (Figura 2), a captura corrigida (CC) pode representar melhor a composição da captura nesta região, sem os vícios relacionados à comercialização. $\mathrm{A}$ proporção de tambaqui na captura corrigida (CC) ou no desembarque pesado (PP) apresentou valores similares para os anos analisados, com valores variando entre 3 e $5 \%$. A relação $\mathrm{PP} / \mathrm{CC}$ indica a percentagem do que é comercializado em Tefé do total capturado pela frota que desembarca nesta cidade, que variou de 30 a $55 \%$, tanto em relação à captura de tambaqui quanto à captura total, para os anos de 1991 a 1995. O restante representa a quantidade de pescado que foi transportada para outras cidades, como Manaus, ou foi desviada do mercado para o consumo interno. As espécies que são desviadas da pesagem para o consumo interno são em geral aquelas de maior valor comercial, com destaque para os tambaquis de maior porte (Tab. 3).

A Figura 4 apresenta a distribuição mensal da captura corrigida (CC) de tambaquis e a flutuação do nível da água. O período engloba cinco estações de

Tabela 3. Quantidade de pescado pesado (PP) e da captura corrigida (CC) da frota que desembarcou no mercado de Tefé, considerando todas as espécies e somente o tambaqui, Amazonas, Brasil.

\begin{tabular}{|c|c|c|c|c|c|}
\hline & 1991 & 1992 & 1993 & 1994 & 1995 \\
\hline \multicolumn{6}{|l|}{ PP } \\
\hline Total (kg) & 428.771 & 1.659 .730 & 1.471 .463 & 1.707 .215 & 1.057 .262 \\
\hline Tambaqui (kg) & 13.637 & 61.901 & 58.271 & 44.049 & 52.787 \\
\hline Tambaqui/ Total & $3 \%$ & $4 \%$ & $4 \%$ & $3 \%$ & $5 \%$ \\
\hline \multicolumn{6}{|l|}{$\mathrm{CC}$} \\
\hline Total (kg) & 882.357 & 3.524 .566 & 3.621 .486 & 4.245 .761 & 3.582 .383 \\
\hline Tambaqui (kg) & 24.823 & 137.459 & 133.325 & 115.362 & 147.261 \\
\hline Tambaqui/ Total & $3 \%$ & $4 \%$ & $4 \%$ & $3 \%$ & $4 \%$ \\
\hline \multicolumn{6}{|l|}{$\mathrm{PP} / \mathrm{CC}$} \\
\hline Total & $49 \%$ & $47 \%$ & $41 \%$ & $40 \%$ & $30 \%$ \\
\hline Tambaqui & $55 \%$ & $45 \%$ & $44 \%$ & $38 \%$ & $36 \%$ \\
\hline
\end{tabular}


seca, de 1991 a 1995 , e quatro estações de cheia, de 1992 a 1995. Os meses de maior captura se deram durante a cheia, nos anos de 1992, 1993 e 1995, e na descida das águas, em 1994; e os de menor captura estiveram relacionados com o período de enchente. A correlação entre o nivel médio mensal do rio e a estimativa da captura mensal de tambaquis não apresentou valores significativos $(\mathrm{P}>0,40$ e $r=0,114)$.

(e) Distribuição de comprimento dos tambaquis desembarcados no mercado de Tefé

Mediu-se 19.969 exemplares de tambaquis entre agosto de 1993 e dezembro de 1995 , no mercado de Tefé. O comprimento mínimo obtido foi de $20 \mathrm{~cm}$ e o máximo de $95 \mathrm{~cm}$, com média de $43,8 \mathrm{~cm}$. Desse total, somente $8,9 \%$ dos indivíduos ou $18,2 \%$ do total em peso tiveram comprimento superior a $55 \mathrm{~cm}$, tamanho minimo de captura do tambaqui permitido pela legislação que regulamenta sua pesca (Portaria $n^{2} 1534 / 89$ ). Esta contribuição variou nos anos estudados, chegando a representar menos de $5 \%$ do total de indivíduos e $1 \%$ do total em peso dos tambaquis desembarcados no ano de 1994 (Tab. 4).

\section{(f) Preços do tambaqui}

Em Tefé, foi observado que o tambaqui tem o seu valor de venda atrelado ao seu tamanho (Tab. 5).

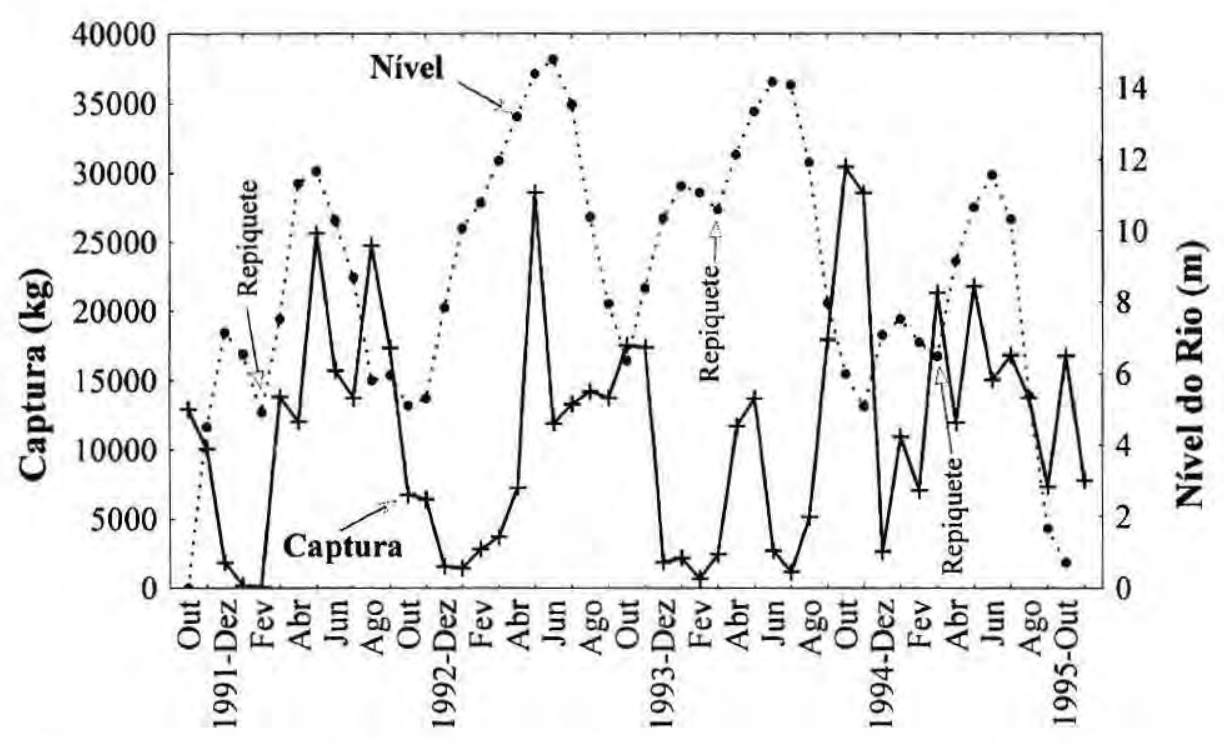

Figura 4. Captura corrigida de tambaquis $(\mathrm{kg})$ da frota pesqueira que desembarca em Tefé e nivel hidrométrico médio mensal (m) em Tefé, de outubro de 1990 a outubro de 1995, Amazonas, Brasil. 
Como o mercado de Manaus valoriza ainda mais os tambaquis maiores, os comerciantes de Tefé passaram a enviar cargas de tambaquis de maior porte para esta cidade por meio dos barcosrecreios, barcos de passageiros que também transportam cargas. Este pescado não chega a ser desembarcado no mercado de Tefé ou de Manaus, sendo recebido diretamente pelo seu comprador no momento da chegada em Manaus.

\section{(g) Captura por aparelho de pesca e habitat}

De um total de 566 toneladas de tambaquis capturados entre outubro de 1991 e novembro de 1995 , cerca de 335 toneladas ou $59 \%$ foi obtida de pescarias que utilizaram apenas um dos 11 tipos de apetrechos listados na Tabela 2, sendo que as capturas com malhadeira e redinha representaram $92 \% ; 71$ e $21 \%$ respectivamente, deste total. A captura da malhadeira não apresentou correlação significativa com o nivel do rio, mas a captura mensal da redinha foi inversamente relacionada com o nivel médio mensal do rio $(\mathrm{P}<0,05, \mathrm{r}=-0,47)$, com produção maior nos períodos de água baixa.

Considerando as entrevistas em que se mencionou a pesca em somente um tipo de ambiente, foi possivel identificar a procedência de 472 toneladas de tambaquis ou $83 \%$ do total capturado. Lagos e áreas alagadas (lago, igapó e ressaca) são os ambientes mais importantes para a pesca do tambaqui, tendo sido a origem de $85 \%$ de sua captura. Não houve correlação significativa entre as capturas mensais nesses ambientes e o nivel médio mensal do rio.

Tabela 4. Percentagem em peso e número de individuos de tambaquis desembarcados no mercado de Tefé que apresentaram comprimento igual ou inferior a $55 \mathrm{~cm}$, tamanho mínimo de captura do tambaqui permitido pela legislação que regulamenta sua pesca, Amazonas, Brasil.

\begin{tabular}{lllll}
\hline & 1993 & 1994 & 1995 & Total \\
\hline Peso & $79,8 \%$ & $99,3 \%$ & $97,6 \%$ & $81,8 \%$ \\
Número de indivíduos & $93,5 \%$ & $95,4 \%$ & $85,0 \%$ & $91,1 \%$ \\
\hline
\end{tabular}

Tabela 5. Preços (US\$) praticados para o quilo do tambaqui por faixa de tamanho no mercado de Tefé nos anos de 1994 e 1995, Amazonas, Brasil.

\begin{tabular}{lc}
\hline Tamanho $(\mathrm{cm})$ & Preço (US\$) \\
\hline$\leq 55$ & $0,60-0,70$ \\
$>55$ e $\leq 65$ & $1,50-1,70$ \\
$>65$ & $2,50-3,00$ \\
\hline
\end{tabular}


Considerando as entrevistas em que se empregou um tipo de apetrecho e se pescou num tipo de ambiente, foi possivel identificar a procedência e 0 apetrecho de pesca que capturou 300 toneladas de tambaqui ou $53 \%$ do total. A Tabela 6 apresenta o cruzamento dessas duas informações, destacando a importância da pesca de malhadeira, rede-malhadeira e redinha, que em lagos e áreas alagadas capturou 78,3\% e em rios e suas margens $14,8 \%$.

\section{(h) Acompanhamento de pescarias}

Foram acompanhadas 11 pescarias comerciais a bordo de embarcações da frota pesqueira de Tefé, na região do médio Solimões e nos períodos de enchente, cheia, vazante e seca de 1994 e 1995.
No início da enchente, geralmente entre outubro e novembro (Figura 4), as pescarias de tambaquis ocorrem, basicamente, em dois tipos de ambientes: "enseada-pausada" e lago. Os tambaquis que são capturados em "enseada-pausada" são em geral de maior porte que os capturados em lagos no mesmo período, atraindo por isso a atenção dos pescadores para este ambiente. A Figura 5 apresenta os comprimentos médios, os limites do desvio padrão e os máximos e mínimos para 525 exemplares capturados em "enseada-pausada" (EP) e 595 exemplares capturados em lagos (LG), obtidos de amostras da captura de 11 pescarias comerciais realizadas entre 30/9/94 e 9/11/95. Os

Tabela 6. Percentagem da captura de tambaqui em relação ao aparelho de pesca e habitat, considerando as entrevistas obtidas em Tefé, entre outubro de 1991 e novembro de 1995, em que somente um tipo de aparelho ou habitat foi mencionado (- não há dados; $0,0 \%$ valor pequeno), Amazonas, Brasil.

\begin{tabular}{|c|c|c|c|c|c|c|c|c|c|}
\hline \multirow[b]{2}{*}{ Aparelho Pesca } & \multicolumn{4}{|c|}{ Lagos e áreas alagadas } & \multicolumn{4}{|c|}{ Rio e suas margens } & \multirow[t]{2}{*}{ Total } \\
\hline & lgapó & Lago & Ressaca & Boca & Enseada Pausada & Paraná & Praia & Rio & \\
\hline Arpâo & - & $0,3 \%$ & - & $0,0 \%$ & . & $0.0 \%$ & - & - & $0,4 \%$ \\
\hline Arrastadeira & - & $0,0 \%$ & - & . & - & $0,1 \%$ & . & - & $0,2 \%$ \\
\hline Caniço & $0,1 \%$ & $0,2 \%$ & $0,0 \%$ & - & - & - & . & - & $0,2 \%$ \\
\hline Espinhel & $0,0 \%$ & $3,4 \%$ & $0,0 \%$ & - & - & $0,3 \%$ & - & - & $3,8 \%$ \\
\hline Flecha & - & $0,2 \%$ & $0,0 \%$ & $\cdot$ & . & $0.0 \%$ & : & - & $0.3 \%$ \\
\hline Linha de Mão & - & $0,3 \%$ & - & - & . & . & - & - & $0.3 \%$ \\
\hline Malhadeira & $0,3 \%$ & $63,0 \%$ & $0,7 \%$ & $1,0 \%$ & $0,4 \%$ & $2,6 \%$ & $0.2 \%$ & $2,9 \%$ & $71,1 \%$ \\
\hline Rede-malhadeira & - & $4,5 \%$ & $=$ & - & , & . & - & . & $4,5 \%$ \\
\hline Redinha & - & $9,8 \%$ & $\cdot$ & $2,3 \%$ & $2,6 \%$ & $0,2 \%$ & $0.1 \%$ & $2,6 \%$ & $17,6 \%$ \\
\hline Tarrafa & - & $0,1 \%$ & $0,0 \%$ & $0.0 \%$ & - & - & - & - & $0,1 \%$ \\
\hline Zagaia & - & $1,3 \%$ & - & - & $0,0 \%$ & $0,3 \%$ & - & - & $1,6 \%$ \\
\hline Total & $0.4 \%$ & $83,1 \%$ & $0,8 \%$ & $3,3 \%$ & $3,0 \%$ & $3,6 \%$ & $0,3 \%$ & $5,5 \%$ & $100,0 \%$ \\
\hline
\end{tabular}


tambaquis provenientes de "enseadapausada", possuiam comprimentos variando entre 42,5 e $102 \mathrm{~cm}$ e mais de $70 \%$ mediam tamanho igual ou superior a $55 \mathrm{~cm}$. Os tambaquis capturados em lagos possuiam comprimentos variando entre 40 a $67 \mathrm{~cm}$ e somente $23 \%$ mediam tamanho igual ou superior a 55 $\mathrm{cm}$ (Fig. 5). Ressalta-se que o comprimento médio dos indivíduos capturados em lagos seria ainda menor se fossem incluidos os peixes com comprimento inferior a $40 \mathrm{~cm}$, descartados durante a pescaria devido ao seu pequeno valor comercial. As medianas dos comprimentos obtidas em enseada-pausada $(n=525)$ foram estatisticamente superiores aos obtidos em lagos ( $\mathrm{n}=595)$ (Teste Kruskal-Wallis: $\mathrm{H}_{(1, \mathrm{~N}=1120)}=323,2584 \mathrm{p}<0,001$; Teste da Mediana: Qui-quadrado $=251,6601$, Graus de liberdade $=1, p<0,001$ ).

O curso médio do rio Solimões é bastante meandrado, favorecendo o surgimento de ambientes como "enseada-pausada". Um inventário realizado em 1994 ao redor da Reserva de Desenvolvimento Sustentável Mamirauá, situada entre os rios Solimões, Japurá e Aranapu (Figura 2), identificou 26 áreas de "enseadapausada", todas poten-cialmente exploradas pela pesca local. A pesca neste ambiente é feita com a redinha, necessitando de perícia dos pescadores para posicionar a rede entre as áreas de forte correnteza do rio e de troncos e paus da enseada. Ela é feita com uma canoa grande, que conduz os pescadores e a rede, e uma canoa pequena, que serve para apoiar uma das pontas da rede de cerco. A princi- pal função desta pescaria é a do proeiro, que é reconhecidamente o pescador mais experiente do grupo e o responsável pela localização do cardume e pela habilidade de lançar a rede no momento e local certos. A pesca tem início quando o pescador identifica a presença de cardumes de tambaqui na "enseada-pausada:, que é percebida pelo barulho que os peixes fazem na superfície d'água, denominado de "rebojo". Existe uma forte crença por parte dos pescadores de que o peixe faz esse ruido quando está acasalando. Esse som é imitado continuamente pelo proeiro, usando um remo, até ter o retorno do baruiho pelo peixe. Caso isso não ocorra e nenhum outro movimento aguce a atenção do pescador, a pesca é dada por encerrada nesta área sem sequer a rede ter sido lançada na água e uma nova pausada é procurada. Se o peixe "responde" a esse movimento do remo, o pescador lança a rede no local do "rebojo".

Com a subida das águas, os ambientes de enseada-pausada desaparecem e os peixes se dispersam com o surgimento das primeiras áreas alagadas, tornando sua captura mais difícil. Neste período, determinados aparelhos de pesca, como redinha e arrastadeira, perdem sua eficiência, pois não podem ser usadas nas áreas recém alagadas e a malhadeira passa a ser o apetrecho mais eficiente para a captura de grandes tambaquis. Outros equipamentos como o espinhel e, eventualmente, até a redinha, são utilizados na pesca do tambaqui durante a enchente, quando os peixes 


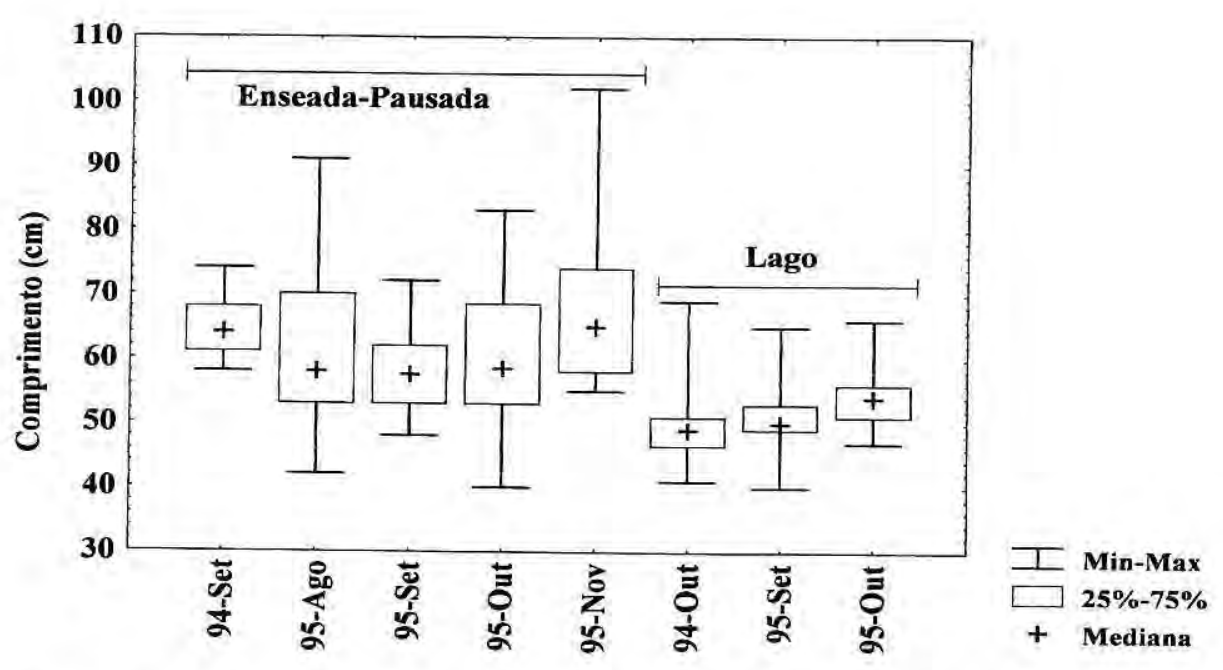

Figura 5. Mediana (+), quartil (caixa) e máximo e mínimo dos comprimentos de tambaquis obtidos em diferentes meses nos ambientes de enseada-pausada e lago na região do médio Solimões, Amazonas, Brasil.

procuram entrar nos lagos que estão sendo alagados. No caso da malhadeira, além do seu uso como aparelho de espera passivo, geralmente feito por um único pescador, é também comum seu uso com o artifício da "batição". Nesse procedimento, que envolve um grupo maior de pescadores, parte do lago é cercada com malhadeiras e os peixes são afugentados para a sua direção por meio de sons produzidos com as batidas de varas na superfície da água e das macrófitas emergentes.

Durante a enchente pode ocorrer um "repiquete", que vem a ser uma parada na subida das águas, seguida de uma queda e logo depois pela retomada da subida normal do nível do rio. $\mathrm{Na}$ época do estudo, ocorreu o repiquete com muita intensidade nas enchentes de 1992, 1994 e 1995 (Fig. 4). Quando o repiquete ocorre antes das águas atingirem os lagos, o que normalmente se dá no final de dezembro, a pesca do tambaqui nos lagos permanece produtiva até o final de fevereiro. Mas quando o repiquete ocorre num periodo posterior, quando a floresta já começou a se alagar, formando o "igapó", o aumento do volume do corpo d'água e a ausência das margens permite a dispersão e proteção dos peixes e a pesca se torna pouco eficiente no interior desses ambientes.

No período compreendido, geralmente, entre março e junho, a mata está alagada e não há lagos isolados. Os pescadores passam a explorar as áreas de mata inundada, procurando os peixes que migram para essas áreas para se alimentar de frutos e sementes, que são abundantes nesse período. Nesse ambiente, os aparelhos mais usados para capturar o tambaqui 
são a malhadeira e o espinhel. Estes apetrechos são estendidos tanto de dia quanto de noite em locais próximos às árvores produtoras de frutos, que servem de alimentação para o tambaqui, como a seringa barriguda (Hevea spruceana) e o jauari (Astrocaryum jauari). A captura de tambaquis em grande quantidade é dificultada pela presença da floresta alagada e pela enorme área de dispersão. Nesta época, o tambaqui chega a desaparecer por até algumas semanas no mercado de Tefé.

A pesca de tambaquis durante a vazante é feita com maior intensidade nas margens do rio Solimões com arrastadeira, redinha e malhadeira. Os pescadores denominam essa época de "migração do peixe gordo" e a arrastadeira é um dos apetrechos mais eficientes neste periodo. As áreas nas margens onde esse apetrecho de pesca é utilizado são denominadas de "lanços". Entretanto, no início da vazante, grande parte da floresta ainda permanece alagada e o uso da malhadeira é ainda freqüente, pois o tambaqui tende a permanecer na floresta alagada enquanto este ambiente persiste.

No período de seca, os lagos estão completamente isolados do rio e a pesca do tambaqui é feita nos lagos principalmente com malhadeira. Embora a captura de tambaquis nos lagos seja bastante produtiva para a pesca comercial, capturam-se comumente indivíduos jovens. Nos rios, a ausência de contato entre o rio e floresta torna a pesca de indivíduos adultos pouco produtiva. Os pescadores locais acreditam que os grandes tambaquis permanecem no canal migrando rio acima até o inicio da enchente, quando começam a se concentrar novamente na "enseadapausada".

\section{DISCUSSÃO E CONCLUSÃO}

A pesca comercial de tambaqui tem importância nas bacias dos rios Orinoco e Amazonas, principalmente em regiões próximas às extensas áreas alagáveis dos vales destes rios (Araújo-Lima \& Goulding, 1997). O desembarque de tambaqui nos mercados dos centros urbanos destas regiões apresenta sempre uma posição de destaque, já atingiu valores próximos a $21 \%$ da produção de pescado de alguns centros urbanos da bacia do Orinoco, 3\% da Amazônia peruana e $35 \%$ da Amazônia boliviana. No Brasil, na região do rio Madeira, a importância relativa da captura do tambaqui aumentou de $10 \%$ em 1977 para $20 \%$ entre 1984 e 1989. Em Manaus, a espécie já respondeu por $40 \%$ do pescado desembarcado, mas nos anos 80 e 90 sua produção sofreu uma grande diminuição, passando a oscilar entre 2,5 e $27 \%$ (Novoa \& Ramos, 1978; Petrere Jr.,1978b, 1983; 1985; Goulding, 1979; Merona \& Bittencourt, 1988; Lauzanne et al., 1990; Boischio; 1992; Ruffino \& Isaac, 1994; Barthem et al., 1995; Barthem, 1995; Batista, 1998).

Apesar da cidade de Belém estar situada próxima às extensas áreas alagáveis, distribuídas nas diversas ilhas da foz amazônica e ao longo da 
costa do Pará e Amapá, a importância do tambaqui em seus mercados é pouco expressiva. Isto se deve à diferença entre a natureza destas áreas alagáveis: as da foz são alagadas pela chuva e maré e as do vale do rio Amazonas são alagadas pelo transbordamento dos rios. Estas últimas são denominadas de várzea e igapó, as quais Goulding \& Carvalho (1982) mostraram ser de vital importância para o ciclo de vida do tambaqui.

A região do médio Solimões apresenta uma extensa área alagada na confluência dos rios Solimões e Japurá, incluindo os paranás AuatiParaná (acima da foz do rio Jutaí) e Copeá (acima da cidade de Coari) (IBGE 1977 ). Esta é uma das regiões que Petrere Jr. (1985) destacou como importante área de pesca para o tambaqui desembarcado em Manaus no final dos anos 70. A pesca nesta região utiliza uma grande variedade de apetrechos de pesca, cujo uso varia de acordo com a espécie a ser capturada, a época do ano, o ambiente e o nivel do rio. Para a pesca comercial do tambaqui são empregados 11 tipos de aparelhos de pesca, sendo que a malhadeira e a redinha foram responsáveis por mais de $90 \%$ de toda a captura. Esta situação não difere daquela descrita anteriormente para a pesca de tambaqui em outras áreas da Amazônia (Honda et al, 1975; Petrere Jr., 1978a;b; Goulding, 1979; Smith, 1979; Merona \& Bittencourt, 1988). No entanto, deve-se destacar que as pescarias atuais incidem principalmente em tambaquis jovens $(<55 \mathrm{~cm})$, de tamanho inferior ao permitido pela legislação que regulamenta sua pesca (Portaria $\mathrm{n}^{\ell}$ 1534/89). A percentagem média de jovens na composição em tamanho dos tambaquis desembarcados foi de $91 \%$ em número de indivíduos, ou $82 \% \mathrm{em}$ peso, para o período entre agosto de 1993 e dezembro de 1995. Porém, esta percentagem variou de ano para ano, chegando a atingir valores extremos de $95 \%$ e $1 \%$. Estes valores se aproximam dos obtidos por Ruffino \& Isaac (1994) no baixo Amazonas, que constataram que os jovens representavam $90 \%$ da captura em termos de número de individuos. Nesta região, Isaac \& Ruffino (1996) mostraram que a pesca sobre os tambaquis é excessiva e que estaria conduzindo este estoque a um estado de sobrepesca.

A pesca do tambaqui está intimamente relacionada aos movimentos e comportamento da espécie e às flutuações no nivel do rio. No entanto, a alta produtividade da malhadeira durante todo o ano mascara a correlação entre a captura e o nivel do rio, principalmente pelo fato dos jovens serem vulneráveis $o$ ano todo. Além disso, aparelhos de pesca como a redinha tem seu uso limitado a determinada época do ano, sua utilização em "enseada-pausada", onde este apetrecho é produtivo para indivíduos de maior porte, está condicionada a um periodo que raramente ultrapassa um mês. A pequena quantidade de captura com redinha e arrastadeira reflete também a dominância da captura de indivíduos jovens, pois estes aparelhos são mais 
produtivos na pesca de tambaquis adultos, comumente capturados em rio e "enseada-pausada", no início da enchente.

A concentração de tambaquis maiores na "enseada-pausada", no início da enchente, torna este período bastante lucrativo para os pescadores que possuem redinha. Nesse período do ano, os barcos de pesca chegam a se deslocar até Tabatinga (a $1.686 \mathrm{~km}$ de Manaus e a $1.321 \mathrm{~km}$ de Tefé) explorando as áreas de "enseada-pausada" atrás dos tambaquis maiores. A grande demanda nos principais centros urbanos por tambaquis com comprimento superior a $60 \mathrm{~cm}$ e a dificuldade de capturá-los fora do período reprodutivo, tem motivado a prática de um comércio paralelo em Tefé, principalmente através dos barcos recreio (que originalmente servem de transporte de passageiros). Nesse caso, os peixes maiores são comprados para serem revendidos diretamente a restaurantes e peixarias de Manaus. Tal particularidade deve ter influenciado a baixa freqüência desses peixes nos mercados da região, aumentando com isso a importância dos tambaquis jovens na composição em tamanho dos peixes desembarcados.

A exploração de tambaquis em lagos de várzea da Amazônia é realizada há muito tempo, sendo registrada desde o século passado (Verissimo, 1970). Entretanto, nas últimas décadas, a exploração intensa desses lagos pela frota que abastece os principais mercados da região, vem sendo um dos principais motivos de conflito entre pescadores profissionais e ribeirinhos (Hartmann, 1989; McGrath et al, 1993). Na região, fo- ram comuns os relatos de conflitos entre comunitários e barcos oriundos de Manaus. Menos comuns foram os conflitos com barcos de pesca local, que normalmente exploram o lago com o consentimento da comunidade ou do líder comunitário. Na região, esta forma de comercialização é conhecida como "arrendamento do lago" no qual, subtraidas as despesas com a viagem, $50 \%$ do lucro fica com a comunidade. Porém, conflitos entre moradores de uma mesma comunidade podem, em alguns casos, gerar discussões sobre a autorização concedida ao barco de pesca para explorar determinado lago.

Do ponto de vista do manejo do recurso, os tambaquis são bastante vulneráveis às técnicas e as redes de pesca empregadas quando estão confinados aos lagos de várzea, ambiente chave para os jovens desta espécie. A disponibilidade desses locais para a pesca está diretamente ligada às flutuações no nivel do rio, sendo o repiquete um evento importante, que pode tornar os peixes mais ou menos vulneráveis à pesca. A não existência de um padrão temporal para o repiquete durante o periodo de estudo torna dificil avaliar sua influência sobre a pesca nos lagos da região. Entretanto, é evidente que este retardo na enchente afeta diretamente o tempo de exploração, com reflexos diretos sobre os estoques de peixes nessas áreas, pois quanto maior o periodo de isolamento no interior dos lagos, maior a possibilidade do peixe vir a ser capturado.

\section{AGRADECIMENTOS}

Ao Projeto Mamirauá, ODA, WWF, WCS, CNPq, MPEG e INPA 
pelo suporte financeiro e logístico. Aos colegas de Tefé, em especial Sigueru Esashica e Cipriano, pela ajuda no campo.

\section{Bibliografia citada}

Araujjo-Lima, C.; Goulding, M. 1997. So Fruitful a Fish: Ecology, Conservation, and aquaculture of the Amazon's Tambaqui. Columbia University Press, New York. $191 \mathrm{p}$.

Barthem, R. B. 1995. Developmental of commercial fisheries in the Amazon basin and consequences for fish stocks and subsistence fishing. In: M. Clüsener-Godt and I. Sachs (Eds). Brazilian perspectives on sustainable development of Amazon region. Mam \& the Biosphere Series, 15. UNESCO and The Parthenon Publishing Group. 311 p.

Barthem, R. B. 1999a. Varzea fishery in the middle Rio Solimões. In: Padoch, C., Ayres, J. M., Vasques, M. P. e Henderson, E. (Eds.) Diversity, development and conservation of Amazon white-water floodplain.._New York Botanical Garden, vol. 13: $405 \mathrm{p}$.

Barthem, R. B. 1999b. A Pesca Comercial no Médio Solimões e sua interação com a Reserva de Desenvolvimento Sustentável Mamirauá. In: Queiroz, H. L. e Crampton, W. G. R. (Eds), Estratégias para Manejo de Recursos Pesqueiros em Mamirauá. Sociedade Civil Mamirauá e CNPq, $208 \mathrm{p}$.

Barthem, R. B.; Guerra, H.; Valderrama, M. 1995. Diagnostico de los Recursos Hidrobiológicos de la Amazonia. Tratado de Cooperación Amazonica, Secretaria Pro Tempore. 2nd edición. $162 \mathrm{p}$.

Batista, V. da S. 1998. Distribuição e dinâmica da frota e dos recursos pesqueiros $d a$ Amazonia Central. Tese Doutorado, INPA, Manaus AM. 282 p.

Boischio, A. M. P. 1992. Produção pesqueira em Porto Velho, Rondônia (1984-1989)alguns aspectos ecológicos das espécies comercialmente relevantes. Acta
Amazônica 22 (1): 167-172.

Carvalho, M. L. 1981. Alimentação do tambaqui jovem (Colossoma macropomum Cuvier, 1818) e sua relação com a comunidade zooplanctónica do Lago Grande - Manaquiri, Solimões $A M$. Tese Mestrado, INPA, Manaus AM.

Goulding, M. 1979. Ecologia de Pesca do Rio Madeira. CNPq/INPA, Manaus. 172 p.

Goulding, M. 1980. The fishes and the forest: Explorations in Amazonian natural history. University of California Press, Berkeley, Calif. 280 p.

Goulding, M.; Carvalho, M. L. 1982 . Life history and management of the tambaqui Colossoma macropomum, Characidae): An important Amazonian food fish. Revista Brasileira de Zoologia, I (2): $107-$ 133.

Hartmann, W. 1989, Conflitos de pesca em águas interiores da Amazônia e tentativas para sua solução. In: Pesca Artesanal: Tradição e Modernidade, III Encontro de Ciências Sociais e o Mar. Programa de Pesquisa e Conservação de Áreas Úmidas no Brasil. São Paulo. pp 103-118.

Honda, E. M. S.; Correa, C. M.; Castelo, F. P.; Zapelini, E. A. 1975. Aspectos gerais do pescado no Amazonas. Acta Amazonica 5 (1): 87-94.

IBGE 1977. Geografia do Brasil-região norte. FIBGE, diretoria técnica. Geografia do Brasil. Rio de Janeiro. 466 pp.

INPA 1995. Boletin Estdistico Pesquero Colombiano. Instituto Nacional de Pesca y Acuicultura. División de Sistemas y Estadísticas. Santafé de Bogotá, Colombia. $95 \mathrm{pp}$.

Isaac, V.J.; Ruffino, M.L. 1996. Population dynamics of tambaqui Colossoma macropomum Cuvier 1818, in the Lower Amazon, Brazil. Fisheries Management and Ecology. 3: 315-333

Lauzanne, L.; G. Loubens; B. Leguennec. 1990. Pesca y biologia pesquera en el Mamore Medio (Región de Trinidad, Bolivia). Interciencia 15 (6):452-460.

McGrath, D.; Futemma, C. R.; Amaral, B. D. do; Calabria, J. de A. 1993. Manejo 
comunitário da pesca nos lagos de várzea do baixo Amazonas. In: L.G. Furtado; W. Leitão; A. F. de Melo (Eds). Povos das Águas: Realidade e Perspectivas na Amazônia. Museu Paraense Emilio Goeldi, Belém. 292 p.

Merona, B.; Bittencourt, M. M. 1988. A pesca na Amazônia através dos desembarques no mercado de Manaus: resultados preliminares. Memoria Sociedad de Ciencias Naturales La Salle XLVIII: 433453.

Novoa, D., Ramos, F., Cartaya, E. 1984. Las pesquerias artesanales del Rio Orinoco, sector caicara -Cabruta, Parte I. Memória Sociedad de Ciencias Naturales, La Salle. 121: 163-215.

Novoa, D.F. \& Ramos, F. 1978. Las Pesquerias Comerciales del Rio Orinoco. Corporación Venezolana de Guayana, Caracas, $161 \mathrm{p}$.

Novoa, D. 1990. El Rio Orinoco y sus pesquerias: estado actual, perspectivas futuras y las investigaciones necesarias. In: F. Weibezahn, H. Alvarez, W. Lewis (eds.) - El rio Orinoco como ecosistema. Universidad Simón Bolivar; Fundo Editorial Acta Cientifica Venezolana; Eletrificación del Caroni C.A. (EDELCA); C. A. Venezolana de Navegación (CAVN). Caracas. $430 \mathrm{p}$.

Petrere Jr, M. 1978a. Pesca e esforço de pesca no Estado do Amazonas, 1. Esforço e captura por unidade de esforço. Acta Amazonica 3: 439-454.

Petrere Jr., M. 1978b. Pesca e esforço de pesca no Estado do Amazonas. II. Locais, aparelhos de captura, e estatística de desembarque. Acta Amazonica 3(2): 1-54.

Petrere Jr, M. 1983. Yield per recruit of the Tambaqui, Colossoma macropomum
Cuvier, in the Amazonas State, Brazil. Journal of Fish Biology 22; 133-144.

Petrere Jr., M. 1985. A pesca comercial no Rio Solimões-Amazonas e seus afluentes: análise dos informes do pescado desembarcado no mercado municipal de Manaus (1976-1978). Ciência e Cultura 37 (2): 1987-1999.

Ruffino, M. L.; Isaac, V. U. 1994. The fisheries of the lower Amazon: questions of management and development. Acta Biologica Venezuelica 15 (2); 37-46.

Smith, 1979. A Pesca no Rio Amazonas. INPA, Manaus. $154 \mathrm{p}$.

Veríssimo, J. 1970. A Pesca na Amazónia. Universidade Federal do Pará, Belém. 130p. 